\title{
ИЗУЧЕНИЕ СТИЛЕЙ МЫШЛЕНИЯ ПО ТЕОРИИ СТЕЙНБЕРГА
}

\section{STUDY OF THINKING STYLES ACCORDING TO STEINBERG'S THEORY}

Darwish Shaza

Summary: The educational process is one of the most difficult activities that a teacher must perform. To improve and facilitate this process, the teacher must be familiar with the students' thinking styles in order to use them to define their own teaching method. The article talks about the concept of «thinking style,» the types of thinking styles, and the factors that influence them.

Keywords: styles, abilities, theory, personality, thinking.

\author{
Дарвиш Шаза \\ Аспирант, ГОУ ВО «Московский педагогический \\ государственный университет», г. Москва \\ shazashazada4@gmail.com
}

Аннотация: Образовательный процесс является одной из наиболее сложных деятельностей, которую должен выполнять учитель. Чтобы улучшить и облегчить этот процесс, учитель должен быть знаком со стилями мышления учащихся, чтобы на основе этих знаний определить свой собственный подход к обучению. В статье анализируется понятие «стилей мышления», а также типы данных стилей и факторы, влияющие на них.

Ключевые слова: теория, способности, стиль, личность, мышление.

\section{«Стили» как научное понятие}

Понятие стиля определяется как «характерное физиогномическое единство каких-либо явлений человеческой жизни и деятельности, типичная форма его внешнего выражения». И далее, важнейшая характеристика стиля - он «всегда связан с выражением, активным (сознательным или бессознательным) самопроявлением человека вовне».

\section{Взаимосвязь межАу стилями мышления и Аругими психологическими феноменами}

A - стили мышления и способности («Thinking Styles \& Abilities»). Один из наиболее важных моментов, на которые обратил внимание Р.Стернберг, предложив теорию стилей мышления, заключается в том, что стили не являются способностями, а представляют собой выражение этих способностей. Чтобы понять истинность этого утверждения, необходимо знать какова природа способностей. [1, с.133].

Арабский психолог Аль-Ахмад полагает, что способности являются условиями успешного осуществления определённого рода деятельности и ее компонентов. Он также отмечает, что способности ограничены областью их применения. Например, математические или лингвистические способности связаны с математикой и лингвистикой. В то время как стили мышления существуют во всех областях применения способностей. [14, с.110].

B - стили мышления и типы личности «Thinking Styles \& Personality Туреs». Арабский психолог Рабий отмечает, что разные стили мышления, соответствующие тем или иным типам личности, определяют особенности интеллекта, а значит и склонность к тем или иным видам де- 
ятельности. К тому же цельность человеческой натуры или ее сложность и противоречивость, порождающая множество скрытых внутренних проблем, тоже зависят от стилей мышления, а точнее - от их сочетаний. $[7$, c.35 ], [2, c.285].

C - стили мышления и стратегии мышления «Thinking Styles \& Thinking strategic». Термин «стратегия» является одним из наиболее важных терминов для стилей мышления. Стратегии - это общие методы, используемые людьми при осуществлении умственных действий, то есть способы восприятия, мышления, запоминания, получения информации, ее переработки и решения проблем. [1, с.138 ], [13, с.330].

\section{Определение стиля мышления}

Арабский психолог Аль-Катами отмечает, что стиль мышления - это способ, с помощью которого человек получает, организует и воспроизводит знания, информацию и опыт, и выражается физически и символически через слова и числа.[6, с.77].

Что касается Р. Стернберга, то он определяет стиль мышления как предпочитаемый способ использования имеющихся способностей. Он полагает, что стили не следует отождествлять со способностями, они лежат между личностью и способностями [14, с.19].

\section{Теории стилей мышления}

Исследователи Р.Стернберг и Е.Григоренко отмечают, что существуют три подхода к изучению стилей мышления:

A - Когнитивный подход (Cognition - Centered Styles), ориентируемый на знание. Он является одним из наиболее важных психологических подходов, который до сих пор используется для объяснения поведение человека, описания возможностей его контролировать и направлять. [1, с.127],[15, с.703].

Б - Личностный подход («Personality - Centered Styles») - это понимание личности, как воедино связанной совокупности внутренних условий, преломляющих все внешние воздействия. Одна из основных теорий в этой области - теория психологических паттернов (в общем и целом паттерн в психологии обозначает определенный набор, шаблон поведенческих реакций или последовательностей стереотипных действий относительно любой области, где человек применяет паттерны). Эта теория возникла благодаря работе Карла Юнга и получила развитие у Мейера. Он выделил, четыре основных детерминанты психологических паттернов:

- Чувство и интуиция - это функции сбора (восприятия) информации. Они описывают, как новая информация понимается и интерпретируется.
Люди, предпочитающие ощущения, с большей вероятностью будут доверять информации, которая находится в настоящем, осязаема и конкретна, то есть той, которую можно понять с помощью пяти органов чувств. [9, с.229-231].

- Мышление и чувство - функции принятия решений (суждения). Обе функции мышления и чувства используются для принятия рациональных решений на основе данных, полученных посредством их функций сбора информации (ощущения или интуиции). [6, с.78-80].

Г - Деятельностный подход (Activity - Centered Styles). Ориентируется на реальные действия, которые человек выполняет на различных этапах своей жизни, например, во время обучения и работы; это деятельность человека, направленная на становление его сознания и личности в целом.

В условиях деятельностного подхода человек выступает как активное творческое начало. Взаимодействуя с миром, человек учится строить самого себя. Именно через деятельность и в ее процессе человек становится самим собой, происходит саморазвитие и самоактуализация его личности. Этот подход также пытается дать практическое применение предыдущим подходам (А и Б). Этот подход включает в себя:

1. Стили обучения (Learning Styles). Люди отличаются друг от друга тем, как они учатся. Обучающиеся различаются с точки зрения методов и стилей, которые они предпочитают в процессе обучения. Использование этих индивидуальных предпочтений учителями способствует разработке планов и программ, которые помогают студентам достичь академических целей путем согласования учебного материала с их предпочтительными стилями $[8$, c.130].

2. Стили преnодавания (Teaching Styles). Стиль преподавания отражает те отличительные черты личности и поведения учителя в классе, которые играют важную роль в руководстве учебным процессом и влияют на учащихся и их способность к обучению $[16$, с.11].

\section{Теория ментального самоуправления}

Эта теория является одной из самых последних, которая пытается объяснить природу стилей мышления. Она впервые появилась в 1988 году, как теория ментального самоуправления.

Почему теория ментального самоуправления? Р. Стернберг говорит, что существует множество форм управления нашей деятельностью. Формы управления государством, которые мы видим, являются противоположными образами того, что происходит в нашем сознании. 
Существует своего рода параллель между организацией личности и организацией общества. И мы делаем это так же, как и правительство: нам нужно определить наши источники информации, правительство также стремится к этому; нам нужно реагировать на изменения в нашей социальной среде, правительство также стремится реагировать на изменения и обстоятельства, окружающего мира. И, самое важное, что отличает теорию стилей мышления Р. Стернберга - стили мышления частично зависят от социального взаимодействия, так как предполагается, что они могут быть выработаны и изменены [14, с.19-21].

Турецкий психолог Бисерн Оздемир отмечает, что стили мышления бывают когнитивными, эмоциональными, психологическими, биологическими и социальными, в соответствии с меняющимися стадиями. Когнитивный стиль, потому что когда мы сталкиваемся с проблемой и хотим решать ее по своему предпочтению, то используем некоторые познавательные действия. Эмоциональный стиль, потому что мы используем эмоции в некоторых ситуациях, которые требуют от нас противостояния. Психологический стиль, когда на него влияют личные аспекты, исходящие от человека (способ, которым он говорит, как он сидит, его взгляд). Биологический стиль, когда мышление изменяется в соответствии с изменяющейся средой. Социальный стиль в целом социально приобретен; некоторые общества могут заставить своих членов соблюдать правила и традиции, и это будет в значительной степени способствовать формированию консервативного стиля среди молодежи. [10, с.21-32].

Если представить стили мышления в пространстве человеческого взаимодействия, то мы получим следующую диаграмму (рис. 1).

Е.Григоренко и Р.Стернберг указывают, что теория ментального самоуправления сочетает в себе различные подходы, объясняющие стили. В то же время она имеет свою индивидуальность, отличную от других в интерпретации стилей.

Р. Стернберг классифицировал людей в соответствии с особенностями их мышления на тринадцать стилей, которые разделяются на пять основных групп:

A - Стили с точки зрения функции: 1) законодательный стиль; 2) исполнительный стиль; 3) судебный стиль.

\section{$[12$, c. 1308$],[5$, c.54].}

Б - Стили с точки зрения формы: 1) монархический стиль; 2) иерархический стиль; 3) анархический стиль; 4) стиль олигархический $[2$, с.61],[6, с.100],[4, с.13].

В - Стили с точки зрения тенденции (склонности?): 1) либеральный стиль; 2) консервативный (демократический?) стиль [11, с.34], [1, с.133 ], [16, с.151].

Г- Стили с точки зрения уровня: 1) глобальный стиль; 2) локальный стиль [5, с.843], [16, с.5 ], [15, с.157 ].

Д - Стили с точки зрения направленности: 1) внешний стиль; 2) внутренний стиль [5, с.844 ], [1, с.133 ], $[15$, c.169].

\section{Основные приншипы стилей мышления}

Стили мышления основываются на ряде принципов, которые объясняют характер стилей мышления и области, в которых они могут использоваться, а также ограничения в их применение. Эти принципы состоят следующим:

1. Стили - это предпочтение в использовании способностей, а не сами способности. Если нет разницы между стилями и способностями, тогда вообще не нужна концепция стилей. Стиль является мостом, который связывает способности и личHOCTb.

2. Соответствие между стилями и способностями создает хорошие условия для их успешной интеграции. Такое соответствие лучше, чем использование того или другого по отдельности.

3. Принимаемые в жизни человека решения должны соответствовать стилям и способностям: некоторые люди могут выбирать, например, конкретную специальность или профессию только для того, чтобы своевременно достичь того, чего они хотят [5, c.841], [4, c.10].

4. У человека может быть несколько стилей: инновационный человек может быть хорошо организованным или полностью дезорганизованным.

5. Стили могут меняться в зависимости от разных условий и задач: у нас может быть иерархический стиль в нашей работе, но когда мы дома, то предпочитаем либеральный, а на публике у нас внешний стиль и так далее.
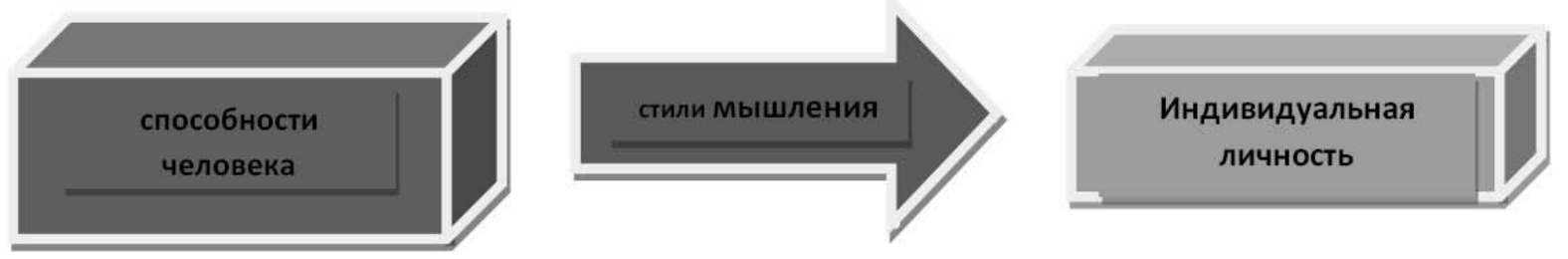

Рис. 1. Место стилей мышления. 
6. Люди отличаются по силе своих предпочтений: некоторые хотят быть и работать в обществе других людей, а некоторые предпочитают одиночество.

7. Люди отличаются своей стилистической гибкостью: чем гибче люди, тем легче они могут адаптироваться ко многим ситуациям [9, с.135-162], $[7$, с.79-81].

\section{Факторы, влияюшие на развитие, формирование} и изменение стилей мышления

На изменения стилей мышления могут влиять следующие важные факторы:

1. Культура общества: каждый социум имеет свою собственную культуру и специфику, которая влияет на поведение людей, так как может поощрять определённые стили и игнорировать другие. Например, консервативное общество может поощрять исполнительный или консервативный стиль и противостоять каждый из них либеральному стилю.

2. Пол: этот фактор оказывает особенно сильное влияние на развитие стилей мышления. Например, мужчин часто описывают как предприимчивых, творческих и раскрепощенных, в то время как женщин как осторожных, застенчивых и послушных. Но это не научный факт, а только отношение общества к полу.

3. Возраст: люди, которые работали в определенной области в течение длительного периода времени, имеют больше свободы для самовыражения, чем те, которые недавно устроились на работу.

4. Родительский стиль: то, что родители поощряют, поддерживают наиболее вероятно, будет отражено в стиле ребенка.

5. Образовательное окружение: большинство школ в мире, как правило, устанавливают ряд стилей (исполнительные, внутренние и консервативные), учитывая традиционные методы обучения и характер разработки учебных программ, поощряют тех, кто охарактеризован этими стилями. Отсюда спокойный, послушный ученик, приверженный школьным законам и этике имеет более высокий статус, это исполнительные и консервативные ученики. Творческие ученики (законодательные, судебные и либеральные) находятся за пределами школьных законов [3, с.73], [7, с.168],[9, с.175].

\section{Выво $ы$ ы}

Из положения о том, что стили мышления являются мостом, связывающим способности и личность, можно сделать следующие выводы:

1. Стили мышления не способны выразить предпочитаемый способ осуществления различных видов деятельности и решения проблем, с которыми сталкивается индивид в своей повседневной жизни.

2. Существует взаимосвязь между стилями мышления, способностями, типами личности и стратегиями мышления.

3. Р. Стернберг классифицировал людей в соответствии с особенностями их мышления на тринадцать стилей, которые разделяются на пять основных групп: функции, формы, тенденции, уровней и направленности.

4. Стили мышления основываются на ряде принципов, которые показывают природу стилей мышления.

5. На изменение стилей мышления могут влиять факторы: культура общества, пол, возраст, образовательное окружение, родительский стиль.

1. Абу Джаду. С, Мухаммад. А, Педагогическая психология.- 2000-. Иордания.

2. Абу Алам. М, Исследовательские подходы в психолого-педагогических науках.- 2007- 4-ое издание, Каир.

3. Абу Фахр. Г, Трудности обучения и их лечение.-2007-. Дамаск.

4. Абу Хашим. С, Психометрические характеристики списка методов мышления по теории Штернберга.-2071-. Саудовская Аравия.

5. Абу Хашем. Г, Камаль. С, Методы обучения и мышления. Отличительные особенности для студентов университетов в свете их уровня достижений и различных академических специальностей.-2008-. Иордания.

6. Аль-Ахмад. А, Исследования и исследования в области психологии.-2012-. Бейрут.

7. Ахмед. М, Инновационное мышление и его связь с пространственным восприятием, воображением и техническими знаниями.-2010-. Дамаск.

8. Американская психиатрическая ассоциация, диагностическое руководство Четвертая статистическая поправка на психические расстройства.-2007- Дамаск.

9. Бутрос. Х, Развитие научных и математических концепций.-2008-. 2-ое издание, Иордания.

10. Джарар. А, Влияние факторов окружающей среды на трудности обучения.-2013-. Иордания.

11. Мухаммад. А, Обучение теоретическому мышлению.- 2007-. Иордания. 
12. Раби. Ш, Справочник по экспериментальной психологии.-2009-. Иордания.

13. Хомс. А, Истоки исследований в психологии.-2015-. 2ое издание, Дамаск.

14. Хаттаб. Н, Обучение мышлению студентов с ограниченными возможностями обучения.-2008-. Иордания.

15. Элдердер. А, Современные исследования в когнитивной психологии.-2014-. часть I, Каир.

16. Элдердер. А, Современные исследования в когнитивной психологии.-2014-. часть II, Каир.

(c) Дарвиш Шаза (shazashazada4@gmail.com).

Журнал «Современная наука: актуальные проблемы теории и практики»

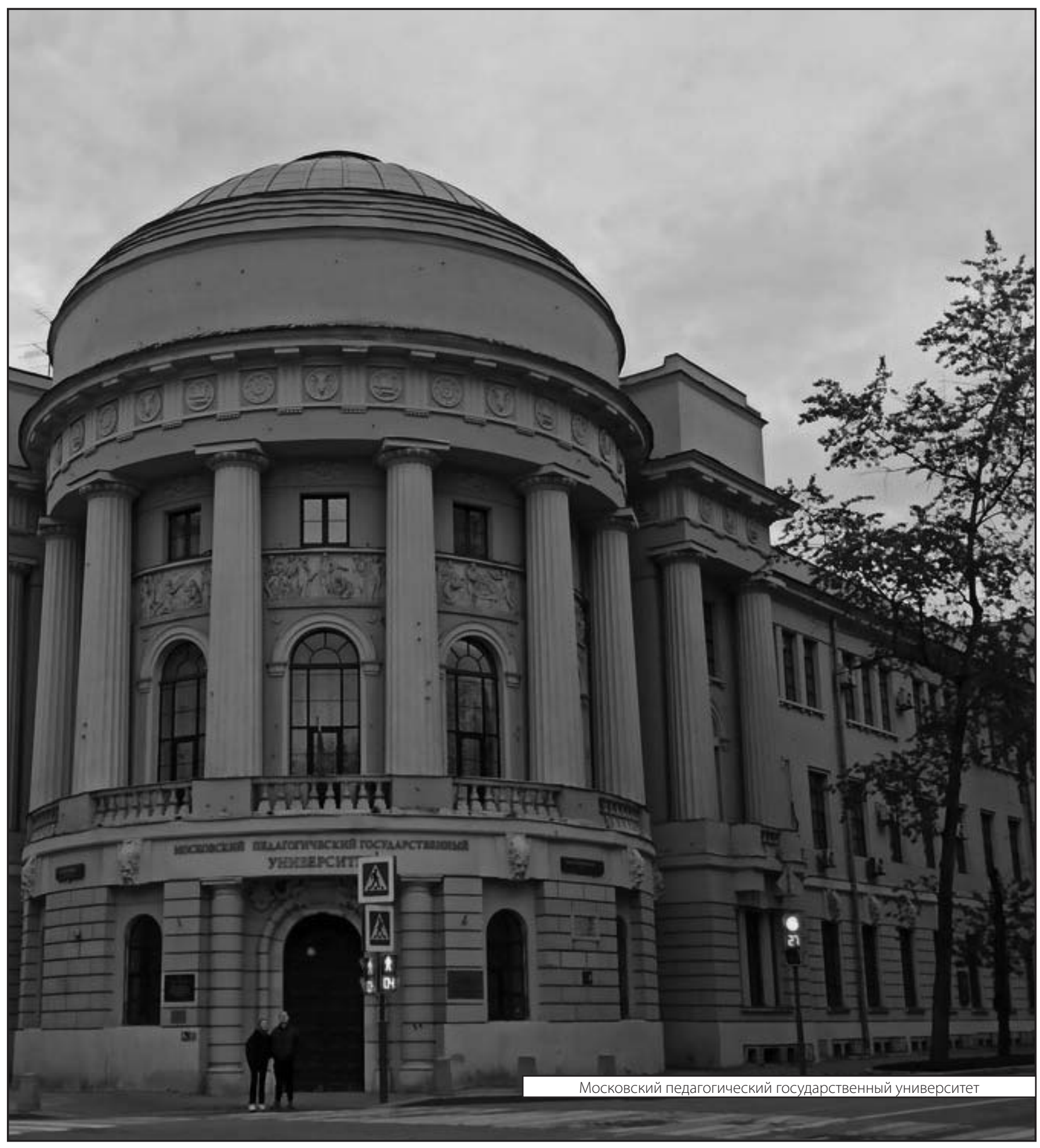

